\section{PTU-110 CIRCULATING BONE MARROW-DERIVED STEM CELLS AND STEM CELL FACTOR SERUM LEVEL IN CHRONIC HEPATITIS C: RELATION TO HEPATIC PROLIFERATION AND FIBROSIS}

doi:10.1136/gutjnl-2013-304907.200

1."H A El Aggan, ${ }^{2} \mathrm{~N}$ M Farahat, ${ }^{3} \mathrm{~B}$ M El Sabaa, 'A S Elyamany, 'R M Abou Esa. 'Department of Medicine (Hepatobilary Unit); 'Department of Clinical Pathology; ${ }^{3}$ Department of Pathology, Faculty of Medicne, University of Alexandria, Alexandria, Egypt

Introduction Bone marrow-derived stem cells (BMSCs) are pluripotent cells that can be mobilised into circulation and recruited to sites of inflammation where they promote local tissue repair. Therefore, the present work was designed to study circulating BM-derived hematopoietic stem cells (HSCs) and mesenchymal stem cells (MSCs) and serum levels of stem cell factor (SCF), a stem cell mobilising factor, in patients with chronic hepatitis $\mathrm{C}(\mathrm{CHC})$ in relation to hepatic proliferation and fibrosis.

Methods Thirty treatment-naive patients with $\mathrm{CHC}$ and 15 healthy subjects were included in the study. The BM-derived HSCs and MSCs cells in fresh blood samples were identified as $\mathrm{CD} 34^{+} \mathrm{CD} 45^{+} \mathrm{CD} 117^{+}$and $\mathrm{CD} 34{ }^{-} \mathrm{CD} 455^{-} \mathrm{CD} 106^{+}$cells respectively using flow cytometric assay. Serum SCF levels were measured using an enzyme linked immunosorbant assaykit. Liver biopsies were examined to assess METAVIR histological activity grade and fibrosis stage and steatosis grade. Immunohistochemical staining of liver specimens was done using monoclonal antibodies against cytokeratin (CK)7 for detection of hepatic progenitor cells (HPCs), Ki-67 as proliferation marker and a-smooth muscle actin (a-SMA) for identification of activated hepatic stellate cells (HpSCs).

Results Patients with CHC showed significant increases in the percentages of HSCs and MSCs in peripheral blood and serum SCF levels compared with healthy subjects $(P<0.05)$. Numerous $\mathrm{CK}^{+}$ HPCs were detected mostly lining primitive bile ducts or as individual positive cells in the portal tracts. Hepatic proliferative activity evidenced as nuclear positivity for Ki-67, was observed in proliferated ductal profiles in portal tracts and within hepatocytes and directly correlated with HPC expansion. Based on the percentages of BMSCs in peripheral blood, patients with CHC were distinguished into two types of patients: "mobilizers" and "non-mobilizers". BMSC mobilizers showed a significant increase in serum SCF levels and significant decreases in HPC expansion, hepatic proliferative activity, serum levels of aminotransferases, histological activity grade, fibrosis stage and a-SMA expression compared with BMSC non-mobilizers $(P<0.01)$.

Conclusion Chronic HCV infection is associated with mobilisation of BMSCs from the BM into the circulation in parallel with an increased production of SCF, particularly when HPC activation and hepatic proliferative activity are impaired. Although the mobilised BMSCs are not sufficient to bring about hepatic repopulation, they may play an important role in limiting hepatic necroinflammation and fibrosis in HCV-induced liver damage.

\section{Disclosure of Interest None Declared}

\section{PTU-111 A PROSPECTIVE STUDY OF INTRAVENOUS PARACETAMOL PRESCRIBING AND ITS USE IN PATIENTS AT RISK OF IATROGENIC PARACETAMOL INDUCED HEPATOTOXICITY}

doi:10.1136/gutjnl-2013-304907.201

\begin{abstract}
1."J A Evans, 'F Sampaziotis, 'D Ismail, 'S Baillie, 'J McGrath. 'Department of Gastroenterology, Watford General Hospital, Herts, UK
\end{abstract}

Introduction Intravenous (iv) paracetamol can cause severe hepatotoxicity and lead to death if inappropriately prescribed $^{1}$. It is increasingly being used for post-operative pain and pyrexia ${ }^{2}$. There is a lack of awareness that paracetamol should be prescribed by weight when used in certain higher risk groups ${ }^{1,2}$; including those weighing less than 50kilos and in malnourished patients ${ }^{3}$. This study assessed iv paracetamol prescribing in patients at increased risk of hepatotoxicity.

Methods Drug charts and medical records from 5 wards (3 surgical and 2 medical including 1 gastroenterology ward) were assessed prospectively over 3 days. All patients prescribed paracetamol were identified; those receiving iv preparations were included. The age, sex and weight were recorded in conjunction with the dose, route and number of paracetamol doses received by each patient. Intravenous doses were identified by countersignatures on drug charts or where iv was the only route indicated. Medical records were reviewed for a history of alcohol excess, chronic liver disease, chronic kidney disease (CKD), eating disorders, and those taking CYP450 inducing medications.

Results 59 patients were receiving paracetamol via any route. The average age was 74.6 years old (range 32-86). 25 patients had received iv paracetamol with $12 / 25$ (48\%) receiving the drug only via the iv route. The mean number of consecutive doses was 4.44 (range 1-28). 3 patients had CKD, 3 patients were on the CYP450 inducer Rifampicin and 1 patient had an eating disorder and CKD. 2 patients receiving iv doses were under $50 \mathrm{~kg}$, one of which had CKD. Of the 9 patients deemed to be at risk of iatrogenic paracetamol induced hepatotoxicity, $0 \%$ had paracetamol prescribed at the recommended reduced dose of $3 \mathrm{~g}$ per day.

Conclusion This study demonstrates that intravenous paracetamol was not being prescribed appropriately. Intravenous paracetamol should be reduced in high risk groups to $3 \mathrm{~g}$ per day (15mg/kg/24 hours). With $25-37 \%$ of all hospital inpatients being deemed at risk of malnourishment ${ }^{4}$ a large patient cohort is at risk of paracetamol induced liver injury. Assessment of nutritional status and improved awareness of higher risk patients is needed to avoid iatrogenic paracetamol induced hepatotoxicity through poor prescribing

Disclosure of Interest None Declared

\section{REFERENCES}

1. Fatal Accident Inquiry into the death of Danielle Welsh. Available at: http://www scotland-judiciary.org.uk/10/715/[Accessed15 Nov 2012]

2. Gray T, Hoffman R, Bateman D. Intravenous paracetamol - an international perspective of toxicity. Clinical Toxicology 2011; 49 : 150-152

3. British National Formulary. Sept 2012.64 : 264-265

4. BAPEN 2012 -http://www.bapen.org.uk/about-malnutrition/introduction-to malnutr ition? showall $=$ \&start $=4$, [Accessed 3rd Jan 2013].

\section{PTU-112 RIFAXIMIN FOR HEPATIC ENCEPHALOPATHY IS COST EFFECTIVE AT REDUCING EMIERGENCY HOSPITAL ADMISSION}

doi:10.1136/gutjnl-2013-304907.202

1.2, J Orr, ${ }^{2} \mathrm{~F}$ Perez, ${ }^{3} \mathrm{H}$ Mitchison, ${ }^{4} \mathrm{M}$ Hewett, ${ }^{4} \mathrm{~S}$ Saksena, ${ }^{5} \mathrm{~J}$ Topping, ${ }^{6} \mathrm{~A}$ Grapes,

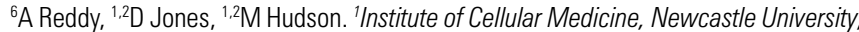
${ }^{2}$ Liver Unit, Freeman Hospital, Newcastle upon Tyne; ${ }^{3}$ Gastroenterology, City Hospitals Sunderland, Sunderland; "Gastroenterology, Univeristy Hospital of North Durham, Durham; ${ }^{5}$ Gastroenterology, South Tyneside Hospital, South Tyneside; ${ }^{6}$ Gastroenterology, Queen Elizabeth Hospital, Gateshead, UK

Introduction Overt Hepatic Encephalopathy (HE) frequently results in emergency admission to hospital. Treatment with the non-absorbable antibiotic rifaximin is effective at preventing recurrence of overt HE but there are concerns about the high cost of the drug. The aim of this study was to evaluate the cost-effectiveness of rifaximin at reducing emergency admission to hospital. 